\title{
Cosificación y experiencia social en la postmodernidad
}

José Manuel Romero Cuevas

Universidad de Granada

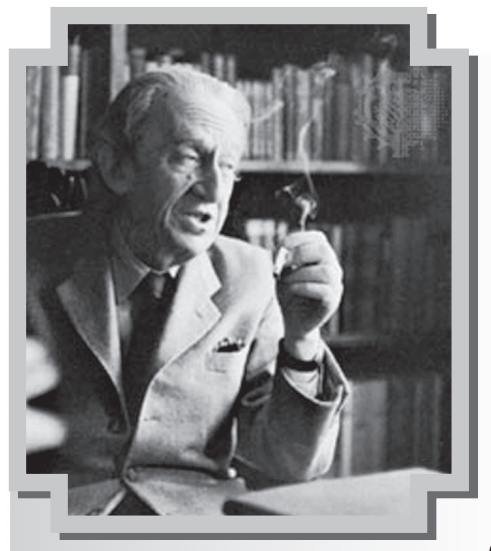

RESUMEN: György Lukács ensayó a comienzos de los años 20 una original y problemática síntesis de neokantismo y marxismo, sosteniendo que la constitución de la objetividad y de la subjetividad venía determinada en el marco de la sociedad capitalista por la forma mercancía. Lukács, de esta manera, pudo sostener que el desarrollo del capitalismo genera toda una serie de procesos de cosificación: la forma mercancía se configura como modelo de toda forma de objetividad y de subjetividad. La experiencia social en la posmodernidad sería una radicalización de esos procesos de cosificación.

ABSTRACT: In the beginning of the 20's, György Lukács proposed an original and problematic synthesis of Neokantianism and Marxism, maintaining that the constitution of both objectivity and subjectivity was determined in Capitalist societies by the 'form merchandise'. So, Lukács could maintain that Capitalist development creates a whole series of reification processes: the 'merchandise form' configures itself as a model of every single form of objectivity and subjectivity. The post-modern social experience would be a radicalization of such reification processes. 
- n un artículo que ocupa una - posición fundacional respecto — a la problemática que orientó la teoría crítica desde W. Benjamin a J. Habermas, G. Lukács ensayó a comienzos de los años 20 una original y problemática síntesis de neokantismo y marxismo, sosteniendo que la constitución de la objetividad (y de la subjetividad) venía determinada en el marco de la sociedad capitalista por la forma mercancía: "No es en modo alguno casual que las dos grandes obras maduras de Marx dedicadas a exponer la totalidad de la sociedad capitalista y su carácter básico empiecen con el análisis de la mercancía. Pues no hay ningún problema de ese estadio evolutivo de la humanidad que no remita en última instancia a dicha cuestión, y cuya solución no haya de buscarse en la del enigma de la estructura de la mercancía. Es cierto que esa generalidad del problema no puede alcanzarse más que (...) si el problema de la mercancía aparece (...) como problema estructural central de la sociedad capitalista en todas sus manifestaciones vitales. Pues sólo en este caso puede descubrirse en la estructura de la relación mercantil el prototipo de todas las formas de objetividad y de todas las correspondientes formas de subjetividad que se dan en la sociedad burguesa." ${ }^{\prime 1}$

Lukács, de esta manera, pudo sostener que el desarrollo del capitalismo genera toda una serie de procesos de cosificación: la forma mercancía se configura como modelo de toda forma de objetividad y de subjetividad. Ello ocurre cuando "esa forma penetre todas las manifestaciones vitales de la sociedad $y$ las transforme a su imagen $y$ semejanza" ${ }^{2}$. En una sociedad en la que se alcanzara esta situación se tendería a una realización en su plenitud de la forma de aparecer de los procesos sociales propia del capitalismo. Lamo de Espinosa ha expuesto claramente en qué consiste esta forma de apariencia social: en el fenómeno social la realidad aparecería desligada de todo proceso, de toda historicidad; lo real aparecería cosificado, velando su historicidad intrínseca. Por otra parte, se mostraría con una pretensión de substancialidad fuerte, con una intensa afirmación de autosuficiencia negando su pertenencia a cualquier tipo de totalidad 3 .

La raíz de esta forma de apariencia social es para Lamo de Espinosa la siguiente: la negación de lo social en el ámbito de la producción en el capitalismo retorna, al modo de lo reprimido, en forma de lógica autónoma (y extraña respecto a los productores) del mercado, de la generación de necesidades y de orientación del aparato productivo. En la lógica del mercado en concreto se expresa especialmente ese esencial fenómeno propio del capitalismo consistente en que los 
productores atribuyen a las mercancías (productos elaborados por su trabajo mediante los que aspiran a entablar relaciones sociales con otros productores) una naturaleza mistificada: una capacidad presuntamente esencial de relacionarse con cualquier otra mercancía, mas según criterios no controlados ni predecibles por los productores. De esta forma, lo que es una relación social entre productores aparece como una relación extrañada entre cosas $^{4}$. La mercancía en el mercado vela su ser resultado de un trabajo social cuya finalidad genuina es relacionar socialmente a los productores entre sí. Ostenta arrogantemente su fantasmagórico valor de cambio como una propiedad natural, se afirma a sí misma como siendo únicamente tal valor, desligada del plano de la producción e interacción sociales entre los hombres. De esta forma, el fetichismo de la mercancía constituiría para Lukács el modelo de las formas de apariencia social bajo el capitalismo, en tanto que lo esencial a éstas es la reificación, es decir, el conferir por parte de los sujetos a las relaciones y procesos sociales, a partir de una oclusión de su ser económico-social, una sustancialidad, una coseidad, que posibilita una perspectiva objetivante, nomológica, que Lukács atribuía a las ciencias sociales burguesas. Este fenómeno fue también concebido por Berger y Luckmann como clave en la constitución de la realidad social tal como es percibida por los sujetos: "La reificación es la aprehensión de fenómenos huma- nos como si fuesen cosas (...), es la aprehensión de los productos de la actividad humana como si fueran algo distinto de los productos humanos (...). El mundo reificado es, por definición, un mundo deshumanizado, que el hombre experimenta como facticidad extraña, como un opus alienum sobre el cual no ejerce un control mejor que el del opus propium de su propia actividad productiva". ${ }^{5}$

La clave de la concepción de Marx del fetichismo de la mercancía es la idea de que el valor de cambio de los productos mercantiles es la manifestación social, en forma de realidad subsistente que alcanza materialización en el precio, del modo en que los trabajos de los productores privados son puestos en relación en el seno de la sociedad competitiva capitalista: mediante el intercambio de los productos de tales trabajos privados. La puesta en relación de equivalencia de las mercancías según una cierta medida para su intercambio genera el valor de cambio, y lo genera como una realidad que acaba dominando a los propios sujetos sociales agentes de la producción, en tanto que éstos están estructuralmente imposibilitados en el seno de la sociedad vigente para coordinar sus trabajos individuales a partir del criterio de la satisfacción de las necesidades colectivas, es decir, atendiendo al valor de uso de los productos de su trabajo. Por ello el valor de cambio no puede ser concebido como una propiedad incorporada en las co- 
sas. Es la expresión de la coacción estructural por parte de las reglas de juego de una sociedad competitiva a la hora de poner en relación los trabajos privados. En tanto que se participa de tales reglas del juego, el valor de cambio es algo que no puede ser eludido y que puede ser calculado con cierta exactitud (como consiguió hacer Marx). El análisis riguroso del valor de cambio exigió a Marx el uso de la categoría de trabajo abstracto, como instancia productora de tal valor. Como tal, esta forma de trabajo no existe. Lo que existe son diferentes formas de trabajo concreto, cualitativo. La categoría de trabajo abstracto es una exigencia del análisis del modo en que el valor de cambio existe, es efectivo y calculable en nuestro mundo social. Ahora bien, no es un mero recurso especulativo. Tal categoría señala la dirección de las transformaciones de las formas de trabajo industrial altamente mecanizado en el seno del capitalismo (aunque la experiencia histórica de la antigua Unión Soviética permite sostener: no solo en el seno del capitalismo), a saber, hacia la abstracción real del trabajo cualitativo en trabajo medible únicamente en tiempo de trabajo humano. Como buen hegeliano, Marx piensa que el capitalismo se va desarrollando históricamente hasta realizar (y coincidir con) su concepto. La categoría de trabajo abstracto, exigida por la teoría del valor, es también una categoría que, al definir una dimensión central del concepto de capitalismo, señala la dirección de su desarrollo y realización.
El valor de cambio es en consecuencia un carácter de los objetos que surge a partir de determinadas reglas de juego sociales; es, como sostiene Žižek, un "efecto estructural" del dominio social las relaciones de intercambio capitalistas ${ }^{6}$. En el marco de tales relaciones posee una objetividad análoga, en cuanto evidencia y consistencia, a la natural. Por ello, el valor de cambio no es una mera alucinación. Es tan real que si una empresa coloca a sus productos un precio absolutamente arbitrario irá con mucha probabilidad a la quiebra. Es real, pero su ser de suyo es relativo a nuestra formación social. Fuera de ella, tal realidad no existe. En nuestro mundo social existe como una realidad constituida a partir de las reglas que definen el juego social. Su consistencia ontológica es histórico-social. Esto no relativiza tal consistencia para nosotros (dentro, por así decirlo, de la jaula): nuestra sociedad está efectivamente dominada por el valor de cambio como la peor de sus fantasmagorías.

El análisis del valor de cambio por Marx podría ser asumido como punto de arranque de una ontología social del capitalismo: como análisis de sus formas de apariencia socialmente necesarias. Este es el camino adoptado efectivamente por Lukács. Las consecuencias ideológicas del fetichismo de la mercancía han sido claramente expuestas por Eagleton: "En virtud de este 'fetichismo de la mercancía', las relaciones humanas aparecen, de manera mistificada, 
como relaciones entre cosas; y esto tiene varias consecuencias de carácter ideológico. En primer lugar, con ello se oculta y se disfraza la dinámica real de la sociedad: se oculta el carácter social del trabajo tras la circulación de las mercancías, que ya no son reconocibles como productos sociales. En segundo lugar (...) la sociedad se fragmenta por esta lógica de la mercancía: ya no es fácil aprehenderla como totalidad, dadas las operaciones atomizadoras de la mercancía, que transforman la actividad colectiva del trabajo social en relaciones entre cosas muertas y discretas. (...) Por último, el hecho de que la vida social esté dominada por entidades inanimadas le da un espurio aire de naturalidad e inevitabilidad".? Eagleton pone de manifiesto los efectos ideológicos fundamentales del fetichismo de la mercancía: fragmentación de la experiencia social, para la cual ya no es aprehensible la totalidad, y naturalización de las relaciones concretas como realidades inertes, cósicas. Este es el núcleo del planteamiento de Lukács: estos efectos ideológicos son las consecuencias esenciales de instauración de la reificación como categoría (en términos análogos a Kant) central de la constitución de la realidad social en el capitalismo. Se debe tener presente en todo momento que para Lukács el fetichismo de la mercancía y la reificación en general no es mera apariencia, sino que se asienta en un substrato de objetividad (las relaciones de producción capitalistas) que no se disuelve con una mera modificación a nivel de consciencia. En este sentido sostiene Eagleton que "la ideología (...) ya no es principalmente una cuestión de conciencia en modo alguno, sino que está anclada en la dinámica económica cotidiana del sistema capitalista. (...) La mistificación, por así decirlo, es un hecho «objetivo», incorporado en el carácter del mismo sistema" ${ }^{8}$. El propio Lukács sostuvo que "las formas de manifestación" propias del capitalismo "no son en modo alguno meras formas intelectuales, sino formas objetivas de la actual sociedad burguesa. Así, pues, su superación, si ha de ser una superación real, no puede ser un simple movimiento del pensamiento, sino que tiene que alzarse a su superación práctica en cuanto formas de vida de la sociedad". ${ }^{9}$

\section{Mercantilización, apariencia social y la posibilidad de una intervención dialéctica}

Hay que ser prudentes a la hora de tomar la forma mercancía tal como la tematiza Lukács (en tanto forma prototípica de la reificación) como modelo de la apariencia en el mundo capitalista, pues puede parecer que se asume tal noción como categoría, en sentido análogo al kantiano, constituyente de la experiencia social en el seno de la 
sociedad moderna, como si fuera la forma fantasmática que es proyectada por doquier espontánea e inconscientemente por los sujetos en el seno de la sociedad productora de mercancías. Frente a esto considero más pertinente tomar los análisis de Marx y Lukács sobre el fetichismo de la mercancía como reflexiones que aportan ideas sugerentes para comprender las transformaciones que sufre la experiencia social en el seno de las sociedades articuladas en torno al mercado capitalista. No pretendo que la forma de mercancía sea sin más la categoría que define la experiencia social en la sociedad productora de mercancías, pero sí creo que los análisis de Marx y de Lukács sobre ella logran explicitar, en un ejemplar desciframiento de elementos de la globalidad social en esa realidad central de la sociedad moderna que es la categoría social de mercancía, motivos productivos que pueden orientar la comprensión de las transformaciones de la experiencia social en el mundo contemporáneo. De esta manera, podemos intentar hacernos cargo, a través de una aproximación diferente a la cuestión, de las consecuencias a nivel de experiencia social de la hegemonía de las relaciones mercantiles sobre el modo de vida social.

Sin separarnos de la letra del planteamiento de Lukács, se puede sostener que la penetración de las relaciones mercantiles en "todas las manifestaciones de la sociedad" a través de la mercantilización integral de la vida social generada por el desarrollo capitalista provoca la conversión de todo valor de uso en valor de cambio. También para Vattimo, el nihilismo, que él define como esa chance que nos abre el acceso a una postmodernidad concebida en términos cuasi-emancipadores, no es sino la culminación de "la transformación del valor de uso en valor de cambio"10. Esa transformación conduce a la extensión de la conciencia mistificada, la cual sólo aprehende lo real desde ese valor de cambio que lo impregna todo. Se trata de una conciencia que naturaliza el marco de relaciones sociales capitalistas a partir de una percepción cosificada de las mismas, percepción que corresponde patentemente a la reiteración continua de estas relaciones en el seno de un marco social que no es jamás transcendido. De esta forma, puede coincidirse con Lukács en que las relaciones sociales bajo el capitalismo tienden a ser percibidas de tal forma que en ellas todo proceso y toda vinculación con la totalidad aparece velada. Una sociedad que llevara a su culminación el proceso anticipado por Lukács, la extensión de la cosificación correspondiente a la mercantilización integral de la vida, tendería en consecuencia a una absolutización de la apariencia propia de los fenómenos sociales en el seno del capitalismo tal como fue pensada por Lukács, es decir, a una pérdida de la historicidad y a una fragmentación radical en los fenómenos sociales que, para Jameson, serían características del postmodernismo. ${ }^{11}$ 
Sería esta naturaleza de la apariencia social en el capitalismo la que daba forma a esa intervención epistémica y política que era la aproximación dialéctica al mundo social circundante. Su estrategia era ahondar a través de las formas de apariencia social sacando a la luz su naturaleza procesual, su ser histórico esencial, y su vinculabilidad a una totalidad social que la teoría crítica de la sociedad debe encargarse de reconstruir. En este sentido, este atravesar la manera objetiva de presentarse los fenómenos sociales tenía una significación política fundamental. Pues nihilizando su ser cosificado y superando su mero ser fragmentado apuntaba a una lectura del presente en el que afloraban dinámicamente un conjunto de posibles que transcendían la forma histórica vigente. La intervención dialéctica, rompiendo la cristalización de lo existente y su dispersión, lo anudaba en una unidad significativa que permitía leer el substrato procesual de esa fenomenalidad, del que manan todo un cúmulo de potencialidades transcendentes respecto del marco presente. Este esfuerzo concluía en una búsqueda sin ilusiones de aquel agente social en condiciones de realizar esos potenciales desplegados por la formación histórica.

\section{La experiencia social en la postmodernidad}

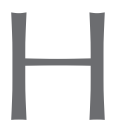

e expuesto cómo en esa sociedad que llevara a su culminación la mercantilización de la vida se tendería a una absolutización de la apariencia social en su forma cosificada en la que tanto su historia y su vinculación con la totalidad quedaría velada. Mas he apuntado cómo históricamente ha existido un tipo de intervención epistémica y política sobre tal apariencia social que ha perseguido romper su ser cosificado y vincular las tendencias dimanantes de la formación social con agentes sociales objetivamente interesados en desplegarlos. Es decir, a pesar de la tendencia del capitalismo a dar consistencia fuerte a su modo de aparecer propio, era posible para una perspectiva teórica y políticamente formada trascender tal modo de apariencia hacia su naturaleza reprimida. Por ello, cuando importantes teóricos de la postmodernidad sostienen que aspectos consustanciales e irrebasables de nuestra época son la definitiva pérdida de la historia y de la totalidad ${ }^{12}$, hemos de sostener que un nuevo factor ha entrado en juego en la definición de nuestra constelación histórica. Pues ha entrado en crisis, se ha dificultado extremadamente, ha devenido quizás infructuosa, esa penetración en la apariencia social posibilitada por la crítica historizadora. Al ser ésta ciertamente una intervención epistémica pero sobre todo política, pode- 
mos aventurar que ha sido un factor de tipo político el que ha conducido a una redefinición de nuestro horizonte histórico y que ha posibilitado la efectiva absolutización de la apariencia. Por tanto, si la reificación del fenómeno social tiene un componente objetivo, fuertemente remarcado por Adorno, ${ }^{13}$ (la forma propia de presentarse la realidad en una determinada formación social según sus relaciones de producción) y un momento subjetivo (la manera en que las conciencias afrontan tal apariencia), será en este segundo componente donde habremos de buscar los cambios relevantes en una perspectiva epocal que definen la culminación de la cosificación de la apariencia hasta alcanzar su absolutización real.

En relación a la cuestión de la postmodernidad, debe distinguirse, por un lado, entre la historia interna del arte y la cultura, su devenir, su desarrollo según una lógica propia (y constatar que la fuente del postmodernismo fue una radicalización extenuante de las neovanguardias artísticas durante los años 60 y principios de los 70 que condujo a la cancelación de su proyecto) $y_{\text {, }}$ por otro, la configuración de ciertos principios, tendencias y corrientes artístico-culturales en definidoras del horizonte cultural de una determinada época. Para esto último son necesarias determinadas condiciones sociopolíticas que posibiliten la conversión de un específico desarrollo artístico-cultural en lo que Jameson denomina pauta cultural o lógica cultural de una dinámica histórica concreta ${ }^{14}$. Entramos en el pantanoso terreno de la relación y mediación entre sociedad y cultura, o bien, entre las formas de realidad social y las representaciones sociales. En este lugar hemos de sostener la siguiente tesis: son determinados desarrollos del proceso político y económico los que posibilitan que pasen a primer plano en la definición de un horizonte social y cultural elementos específicos de los desarrollos producidos según su lógica interna en el campo artístico-cultural. En una problemática diferente (los factores relevantes en la consagración de una determinada forma artística) sostuvo Walter Benjamin en términos análogos que "modificaciones sociales con frecuencia nada aparentes trabajan en orden a un cambio en la recepción que sólo favorecerá a la nueva forma artística"15. De una forma análoga, la relevancia que posee la imagen en la sociedad postmoderna y los efectos subjetivos provocados por la industria de la imagen no se deben quizás a la imagen o a los medios que la usan, en sí mismos. Si fuera así, habría tenido un efecto sobre las subjetividades análogo al actual ya por los años 60. Quizá haya que hablar en consecuencia de determinados cambios epocales que han posibilitado la efectividad de tales efectos sobre los sujetos, cambios en la configuración de las subjetividades que hacen a los individuos radicalmente sensibles y vulnerables a los efectos de la industria mediática. 


\section{$\mathrm{P}$} arece claro que hemos de interrogarnos por ese cambio epocal que pueda dar cuenta de la agudización de la apariencia social y, como se acaba de apuntar, de determinados cambios cualitativos generados en el complejo cultural. La tesis que quiero sostener es la importancia central, para comprender la conversión del postmodernismo en pauta cultural del capitalismo desde finales del siglo XX y los efectos antropológicos de las modificaciones introducidas en el complejo cultural (como el papel de la industria de la imagen), del cambio epocal representado por la crisis de mediados de los 70, que ha determinado el decurso histórico de los últimos treinta y cinco años. 1973 representa la primera crisis económica internacional desde la Segunda Guerra Mundial y posee un significado político definido: supone el comienzo del cuestionamiento y posterior desmantelamiento del Estado del Bienestar en Occidente. La Crisis del Petróleo (así fue denominada) instaló al capitalismo desarrollado en una crisis permanente que sirvió de sustento para la realización de las políticas disolventes del Estado del Bienestar implementadas en el mundo desarrollado en las últimas décadas. En este sentido, el efecto social más importante de esa crisis fue la generación de una crisis generalizada de expectativas que sustituyó a esa confianza en el progreso social que había caracterizado a la conciencia social desde comienzos de los cincuenta. Tan relevante ha sido este efecto que economistas como David Anisi han llegado a dudar de la sustantividad de la crisis del 73 y han apuntado la posibilidad de que determinados sectores sociales estuvieran interesados en la invocación de una crisis que pusiera de manifiesto de manera indiscutible la insostenibilidad del modelo de desarrollo socioeconómico vigente hasta entonces, estructurado en torno al Estado del Bienestar, y condujera a la necesidad de una reestructuración profunda de las relaciones sociales. ${ }^{16}$ Anisi, en consecuencia, sostiene que la crisis del 73 supone en realidad un cambio de estrategia en la lógica de acumulación del capital. ${ }^{17}$ Según su tesis, el pacto social tácito que dio lugar al Estado del Bienestar fue roto por los intereses económicos dominantes a comienzos de los 70. Desde la perspectiva de éstos, el problema estaba claro. Los veinticinco años de Estado del Bienestar habían generado una situación de seguridad laboral sin precedentes a través de políticas de pleno empleo estable que pretendía eliminar las bolsas de desempleo políticamente explosivas. Asimismo, como estrategia activante de un consumo requerido por el desarrollo del aparato productivo y como parte del esfuerzo por integrar 
políticamente a la clase trabajadora, se impulsó un aumento sin igual en la historia humana del nivel de vida de la población. Esto tuvo dos efectos claramente peligrosos para las posiciones que comulgan con la reproducción de lo existente.

Por una parte fue patente, a raíz de las potencialidades de gratificación de las necesidades colectivas ostentadas por el desarrollo del aparato productivo y a tenor de las políticas propias del Estado del Bienestar que realizaban ya algunas de estas potencialidades, que el nivel de satisfacción de las necesidades podía ser elevado. Por otro lado, la relativa seguridad laboral y económica de las clases trabajadoras disfrutada en las últimas décadas hizo perder el miedo a orientarse a una praxis política reivindicativa y en algunos casos anticapitalista. Es decir, fueron generadas por el capitalismo de los años 50 y 60 todo un conjunto de expectativas sobre las posibilidades de generación de gratificación por el sistema productivo, expectativas que arraigaron en formas de subjetividad social fortalecidas por su sostenimiento en una situación de seguridad en su vida material que había arrinconado el miedo social. Todo esto impulsó una agresiva espiral de reivindicaciones y de exigencias que pusieron en claro peligro el pilar central de la economía capitalista: la tasa de beneficio del capital.

De ahí que la "crisis" del 73 permitiera matar varios pájaros de un tiro. Por una parte nos instaló en una crisis financiera de la que ni siquiera los puntos económicos álgidos en los años 80 y 90 parecen habernos hecho salir. De hecho, las políticas europeas actuales, centradas en la reducción del déficit público y el control de la inflación no dejan de ser medidas de choque, justificas sólo por una situación de excepción (que se prolonga desde hace más de 25 años). Estamos en crisis. Este es el horizonte de nuestro tiempo. El efecto fundamental ya ha sido apuntado: nuestra introducción en una experiencia de lo social a partir de una puesta en crisis de la noción de progreso socioeconómi$\mathrm{co}$, desde una desconfianza visceral respecto al porvenir. Todo esto implica llevar a cabo, en definitiva, un cierre del horizonte de expectativas transcendentes al marco económico capitalista. Por otro lado, la crisis del 73 es señal de que el capital ha optado por una reestructuración profunda que posibilite una recuperación de la tasa de beneficio mermada por varios lustros de Estado del Bienestar. Esto se ha traducido en el desmantelamiento de tal forma provisional de desarrollo del capital y en políticas resueltamente agresivas respecto a los sectores asalariados que, a través de una liberalización salvaje de la legislación laboral, ha posibilitado reintroducir condiciones laborales propias del s. XIX que refuerzan las capacidades acumulativas del capital y merman la potencia política del colectivo trabajador. En este último sentido los efectos de la liberalización de la legislación laboral han tenido una 
relevancia antropológica central. Ha introducido una lógica brutalmente individualista en las relaciones laborales, ha sometido a los individuos a una inseguridad radical cuya contrapartida es el sometimiento compulsivo a las exigencias de un mercado laboral estructurado, mediante una permanente coacción política, únicamente según la lógica del beneficio del capital.

Se ha podido hablar consecuentemente de un proceso de desestructuración de la clase obre$\mathrm{ra}^{18}$. Este proceso ha conducido a la constitución de subjetividades instaladas en una inseguridad cuasi-ontológica, hiperdisciplinadas en tanto que completamente vulnerabilizadas respecto a las exigencias del mercado, individualidades instaladas en un horizonte cerrado de expectativas, en el carácter inconcebible de un futuro cualitativamente distinto. En este contexto, considero pertinente traer a colación la categoría zubiriana de desmoralización ${ }^{19}$. La desmoralización nace de la amputación de la apropiación de las posibilidades de realización individual y colectiva abiertas por un determinado horizonte histórico. La consecuencia de ello es la percepción de sí como una mera realidad natural, un en sí sartreano, realidad cerrada, carente de posibilidades transcendentes a su forma actual. Se trata de una subjetividad que vive el presente social tal como Benjamin representaba la experiencia propia de la modernidad, como un retorno de lo igual intranscendente que reitera una y otra vez los momentos de la lógica de la dominación: la experiencia misma del infierno ${ }^{20}$. Una subjetividad así constituida está fragilizada y es máximamente vulnerable respecto a la lógica mercantilista, a la banalización absoluta, a la dispersión y fragmentación radicales que impregnan la industria mediática actual. El haber tematizado en el plano de la teoría este cambio efectivo en la constitución subjetiva como disolución del sujeto (como signatura propia de la sociedad postmoderna), constituye el momento de verdad de determinados planteamientos postmodernistas ${ }^{21}$ Se trata de una individualidad fragilizada respecto a la lógica consumista, la lógica de la mercancía, en la que al fin se hace realidad esa conversión de la mercancía en prototipo de todas las formas de objetividad y subjetividad. Aquí arraiga el otro momento de la experiencia del eterno retorno que Nietzsche supo ver con brillantez ${ }^{22}$. La eliminación de toda expectativa transcendente al marco dado que conduce a la fusión sin fisuras con la mitología consumista reproducida sin cesar por la realidad mediática, aboca a los individuos a un culto irracional, visceral, del presente, los instala en una situación de euforia que no es sino el correlato en el seno de una subjetividad degenerada del terror provocado en la experiencia de lo eternamente retornante.

Llegados a este punto, podemos anudar los diversos temas apuntados. La catástrofe política iniciada con la crisis del 73, con su aboli- 
ción de perspectivas transcendentes al marco vigente y la desestructuración de la clase obrera llevada a cabo en el contexto del proceso de reestructuración del capital, ha generado una vulnerabilización fatal de los individuos que ha posibilitado su sometimiento pleno a la lógica desnuda del mercado y a su cruda mitología. Esta subjetividad vulnerabilizada es la condición tanto de los procesos de despolitización colectiva patente en las últimas décadas como de la efectividad de las consecuencias patológicas de la industria de la imagen. Esto constituye el sustento subjetivo de ese carácter propio del capitalismo actual: la absolutización de la apariencia entendiendo por ésta la extrema dificultad de contrarrestar en la experiencia social colectiva la pérdida de la historia y de la totalidad inherentes a los fenómenos sociales bajo el capitalismo. Esta pérdida de la historia y de la totalidad está en íntima relación con la conversión del postmodernismo (ese desarrollo interno al campo artístico-cultural) en pauta cultural: ha resultado estar en consonancia con las transformaciones de la experiencia en el capitalismo de fin de siglo. En definitiva, la postmodernidad debe ligarse a una coyuntura política de cierre $^{23}$, de instalación en un retorno de lo igual frente al que unas subjetividades, vulnerabilizadas en el plano material y carentes de un horizonte dinámico de expectativas, se encuentran incapacitadas para responder crítica y prácticamente.

\section{NOTAS}

1 Lukács, G., Historia y consciencia de clase, Barcelona, Orbis, 1985, vol. II, p. 7.

2 Lukács, G., op. cit., p. 10.

3 Lamo de Espinosa, E., La teoría de la cosificación. De Marx a la Escuela de Francfort, Madrid, Alianza, 1982, p. 61-2.

4 Marx, K., El capital, México, FCE, 1959, Libro I, p. 36 y ss.

5 Berger, P. y Luckmann, T., La construcción de la realidad social, Buenos Aires, Amorrortu, 1968, p. 116-7.

$6 \quad$ Ver S. Žižek, El sublime objeto de la ideología, México, Siglo XXI, 1992, p. 50 y ss.
$7 \quad$ Eagleton, T., La ideología. Una introducción, Barcelona, Paidós, 1997, p. 118.

8 Eagleton, T., op. cit., p. 119-120.

9 Lukács, G., op. cit., vol. II, p. 120.

10 Vattimo, G., El fin de la modernidad, Barcelona, Gedisa, 1986, p. 25.

11 Jameson, F., El posmodernismo o la lógica cultural del capitalismo avanzado, Barcelona, Paidós, 1991, p. 12 y 21. Sobre esta vinculación entre la experiencia fetichizada de lo social y la concepción de la sociedad de las denominadas metafísicas postmodernas, ver N. Kohan, Fetichismo y hegemonía en tiempos de rebelión, La Habana, Editorial de Ciencias Sociales, 2005. 
attimo efectúa tal constatación en el marco de su crítica a una historia unificada y global, propia de la modernidad (ver G. Vattimo, La sociedad transparente, Barcelona, Paidós, 1992) y Lyotard en el contexto de su concepción de la postmodernidad como deslegitimación de todo metarrelato (ver G. Lyotard, La condición postmoderna, Madrid, Cátedra, 1984). Una concepción historizadora de esta pérdida de la historicidad y de la irrepresentabilidad de la totalidad es efectuada en Jameson, F., op. cit., p 21 y 119.

Ver Th.W. Adorno y W. Benjamin, Correspondencia (1928-1940), Madrid, Trotta, 1998, p. 111 y ss.

14 Jameson, F., op. cit., p. 16 y 21.

15 Benjamin, W., Discursos interrumpidos I, Madrid, Taurus, 1987, p. 49, nota 25 .

16 Ver D. Anisi, Creadores de escasez. Del bienestar al miedo, Madrid, Alianza, 1993, cuya argumentación sigo en lo fundamental

17 Esta es también la tesis de D. Harvey, La condición de la postmodernidad, Buenos Aires, Amorrortu, 1998.

18 Bilbao, A., Obreros y ciudadanos. La desestructuración de la clase obrera, Madrid, Trotta, 1993, p. 39 y ss.

19 Ver X. Zubiri, Sobre el hombre, Madrid, Alianza, 1986, p. 144.
Ver W. Benjamin, Libro de los Pasajes, Madrid, Akal, 2005.

21 Sobre esto, ver mi libro Hybris y sujeto. La ética-estética del joven Nietzsche, Morelia, Jitanjáfora editorial, 2007, p. 153 y ss.

22 En la primera exposición de su pensamiento del eterno retorno, sostuvo Nietzsche: "¿Qué dirías si un día o una noche se introdujera furtivamente un demonio en tu más honda soledad y te dijera: 'Esta vida, tal como la vives ahora y como la has vivido, deberás vivirla una e innumerables veces más; y no habrá nada nuevo en ella, sino que habrán de volver a ti cada color y cada placer, cada pensamiento y cada gemido, y todo lo que hay en la vida inefablemente pequeño y grande, todo en el mismo orden e idéntica sucesión' (...) ¿No te tirarías al suelo rechinando los dientes y maldiciendo al demonio que así te hablara? $¿ O$ vivirías un formidable instante en el que serías capaz de responder: 'Tú eres un dios; nunca había oído cosas más divinas'?”, Nietzsche, F., La Gaya Ciencia, Madrid, M.E. Editores, \$341, p. 211.

E. Lunn considera los años setenta como momento de profundización en el proceso que conduce de la superación de la vanguardia al postmodernismo y ello por el "derrumbe de las esperanzas milenarias de fines de los años sesenta"; Lunn, E., Marxismo y modernismo, México, FCE, 1986, p. 322. 